Open Access

\title{
Unfitting, uncomfortable, unacademic: a sociological reading of an interactive mobile phone app in university lectures
}

\author{
Christopher Drew * (D) and Amandeep Mann
}

\author{
* Correspondence: c.drew@tees.ac. \\ uk \\ Department of Education, School of \\ Social Sciences, Humanities and \\ Law, Teesside University, \\ Middlesbrough TS1 3BX, UK
}

\begin{abstract}
Scholarly literature on education technology uptake has been dominated by technological determinist readings of students' technology use. However, in recent years there has been a move by sociologists of education to highlight how the contexts in which educational technologies are introduced are not tabula rasa but socially and culturally complex. This study approaches technology as a social construct, arguing that students construct discursive meaning of, rather than simply respond to, technologies for learning. The study explores students' constructions of a mobile learning app that was introduced into lectures during a year-long university course. Students largely rejected the app, constructing it as unfitting for the context, a socially uncomfortable experience and an unacademic way of learning. The paper highlights the limitations of technological determinism and closes by arguing for readings of educational technologies that pay close attention to students' voices.
\end{abstract}

Keywords: M-learning, Technological determinism, Social construction of technology, Lectures

\section{Introduction}

Mobile technologies are an increasingly integral part of young adults' lives. Social networking apps on mobile devices like Instagram and Facebook have become online spaces in which users interact, make plans, share experiences, engage in politics and create their identities (Boyd, 2014; Davis \& Gardner, 2013). Aware of contemporary university students' familiarity with online spaces, we introduced a smartphone app to our lectures and encouraged students to use the app to engage in formal synchronous online learning during lectures. The app we chose was Collaborate Ultra, which enabled students to 'chat' online during lecture time and write directly onto the shared lecture slides. It thereby facilitated opportunities for sociable and (inter)active lecture experiences. However, the students broadly rejected the online space, framing it variously as 'unacademic', 'unfitting' and 'uncool'.

This paper explores the students' decisions to reject the online space created for them. The research question was:

(C) The Author(s). 2018 Open Access This article is distributed under the terms of the Creative Commons Attribution 4.0 International License (http://creativecommons.org/licenses/by/4.0/), which permits unrestricted use, distribution, and reproduction in any medium, provided you give appropriate credit to the original author(s) and the source, provide a link to the Creative Commons license, and indicate if changes were made. 
What are a selection of first-year undergraduate students' constructions of an interactive educational app within lectures?

Data was collected through focus group interviews with 38 students randomly selected out of the 106-student cohort. The data was analysed using a sociology of education technology perspective (Jones \& Bissell, 2011; Oliver, 2013; Selwyn, 2012), wherein we examined the data not for exploring how the app 'acted upon' the students, but rather how the students constructed the app as suitable or otherwise for their learning needs (Oliver, 2013). Such a study enables us to highlight how educational technologies are not introduced into a learning scenario that is a tabula rasa ripe to be acted upon; rather, they are introduced into complex social learning environments (Chan, Walker, \& Gleaves, 2015) in which students have expectations, desires and anxieties that should be acknowledged by educators.

Thus, while our year-long interactive app project was originally designed as an opportunity to turn the lecture into something that was more palatable to both our own social-constructivist pedagogical perspectives (Chi, 2009) and students' increasingly tech-engaged ways of interacting (Boyd, 2014), the results render much richer sociological insights. We came to learn that our assumption that students would be enthusiastic about the online spaces if only we provided them was somewhat naive. Indeed, the students widely constructed this interactive mobile app as undesirable for their learning, for a variety of nuanced reasons. The interactive mobile app that we developed was neither how this cohort wanted to utilise their personal mobile technologies nor what they necessarily wanted out of their higher education experience.

\section{Literature review: the case for a sociology of educational technologies}

Sociology of education technology scholarship critiques the dominant 'technological determinist' approach to educational technologies. Through a technological determinist lens, educational technologies are perceived as 'acting upon' student cohorts (Jones \& Bissell, 2011; Kear, Jones, Holden, \& Mark, 2016; Oliver, 2011; Selwyn, 2012; Selwyn \& Facer, 2014; Webster, 2013). Such an approach presumes that the agency to effect change is broadly in the hands of technologies that can coerce students into learning, if only they are set up appropriately. As Selwyn (2012, p. 83) argues,

Throughout the 1980s and 1990s the majority of academic writing was content to imbue educational technologies such as the television and computer with a range of inherent qualities. These qualities were then seen to 'impact' (for better or worse) on young users in ways which were consistent regardless of circumstance or context.

This technological determinism is evident in arguments that accuse games of making youths more violent and overweight; and in arguments selling the transformative effects of gifting students tablet computers at the beginning of a school year. Such claims imply technologies unilaterally act upon learners and often turn out to be overreach.

Studies of the efficacy of mobile learning devices such as web-connected smartphones, tablets and laptops for education have also tended to embrace technological determinist approaches (Chan et al., 2015; Smith, 2016; Wu et al., 2012). Indeed, Wu et al.'s (2012) influential systematic review of mobile learning studies emphasised that literature on mobile learning skews towards positivist and cause-and-effect analyses. This has left some 
scholars to argue for the need for sociological approaches to mobile learning that engage with "cultural and social perspectives" that might "better theorize the phenomenon of smartphone use in learning contexts" (Chan et al., 2015, p. 96).

Thus, recent scholars within the area of the sociology of educational technologies (Selwyn \& Facer, 2014) have called for studies to pursue analyses that recognises the ways that students who are situated within social and cultural contexts approach educational technologies. Sociological analyses of educational technologies can, for example, show that technological artefacts tend to be approached with "interpretative flexibility" (Bijker \& Pinch, 1984, p. 419) inasmuch as technologies are interpreted in different ways in different contexts. Similarly, Oliver (2013) invokes the concept of 'construction' of technologies to highlight how technologies garner meaning only through their contextualised interpretations. Thus, the sociology if educational technology literature takes neither an individualising nor a universalising approach (Zerubavel, 1997) to educational technologies. Agency over the success and failure of technological interventions is seen neither as belonging to individual learners or the technologies themselves. Rather, contextualised understandings of technology usage are required in order to render visible the ways social and cultural factors feed into students' agentive constructions of technology (Selwyn, 2012).

By paying attention to social and cultural implications of educational technologies, scholars have highlighted how educational technologies exist within complex classroom ecologies. As Pedro, Barbados and Santos (Pedro, Barbosa, \& Santos, 2018, p. 11) argue, new technology in a classroom "does not mean that we have the old environment plus one element." Rather, the success of technology integration is associated with a host of contextual challenges. Similarly, Sung, Chang, and Liu (2016) invoke the metaphor of technology 'orchestration' to highlight how technology integration is not as simple as fitting the technology into an existing classroom environment. Instead, ongoing processes of negotiation and collaboration are required in order for the integration to suit the contextualised learning needs of students.

\section{The study's context}

In response to our university's technology enabled learning agenda which encouraged exploration of educational technologies in our classes, we implemented an educational app for use in our weekly lectures. We invited a full cohort of students to log into the Collaborate Ultra app using mobile technologies such as smartphones, tablets or laptops during each lecture for 20 weeks. The students in the study were a largely white working-class female cohort with minimal experiences of university education, studying an introduction to research methods course within the university's Department of Education. The cohort of 106 students was typical of the department's student age demographic, with most students aged 18-24. As we had expected from these young university students, there was no indication throughout the project that any student lacked access to mobile technologies to participate in the study, although students were encouraged to share their screens with others who may not have brought their own devices. Reliable university Wi-Fi was made available to all students.

The app selected for the study was Collaborate Ultra. This app was selected as it enabled students to scrawl directly onto the lecture slides using touch screen capabilities of personal smartphones or tablets. Students' scrawlings on their personal devices was 
automatically projected onto the main lecture slide at the front of the lecture, making the slides a shared space onto which students could make their contributions. Students were also able to type on a shared chat board, which was also projected onto a chat thread on the right-hand side of the slides on the main lecture screen. The lectures, delivered by Author A, spaced four slides of content with two slides of activities. On the activities slides, students were encouraged to collaboratively solve problems and project their answers onto the shared screen. The scrawling option was generally used to draw concept maps or otherwise circle elements of the slide to which they wanted to draw attention. The chat stream was used to make comments or ask questions of the lecturer. Of the 106 students in the course, only an average of 36 students logged onto the software in the first 1 weeks. Logon rates steadily slid from Week 4, until weekly uptake plateaued at 6 students per week from Week 9 onwards.

\section{Methodology}

Given that a sociology of education technology perspective approaches data from an interpretivist paradigm, qualitative semi-structured interviews were selected for the study. Following Smith (2016), we saw interviews with students as the most valuable method for this analysis because it enabled us to gather detailed discussions about how the students constructed the interactive app. At the end of the second semester, 38 students were randomly selected for participation in 8 Focus Groups for semi-structured interviews lasting 20-35 min (Longhurst, 2003). Students were not selected based on their usage patterns but instead were randomly selected so that we could get a broad range of student perspectives of the app. The interviews were conducted by a research assistant (Author B) rather than the lecturer to encourage students to give frank opinions on the topic. Stimulus questions were separated into three categories: students' perceptions of the app's ease of use; students' perceptions of the use of the app's value for learning; and students' perceptions of the app's suitability for lectures. As the interviews were semi-structured and themes were to be induced from the students' conversations, we also encouraged students to 'chat' about the experience in order that the data could emerge through the flow of conversation wherever possible (Vaismoradi, Jones, Turunen, \& Snelgrove, 2016).

The transcriptions of the Focus Group interviews were then analysed. During coding, pseudonyms were used to protect students' privacy, as per the university's research ethics standards. We conducted thematic network analysis (Attride-Stirling, 2001; Clarke \& Braun, 2013; Vaismoradi et al., 2016), which involved three passes over the transcripts. During the first pass, key quotes were highlighted and coded, which were coagulated into themes during the second and third passes over the data. From the transcript analysis, we found three key organising themes that emerged as dominant across the cohort, which are discussed below.

\section{Results}

Three themes emerged from the analysis. Firstly, the students constructed the interactive app as being an awkward fit within a lecture context. The students dominantly saw the ideal lecture as an opportunity to engage in didactic learning (Brown \& Race, 2014; Covill, 2011), which led them to direct their attention towards note-taking, and subsequently construct the interactive app as unfitting for the context. Secondly, the students constructed the app as being an 'uncomfortable' risk to their social subjectivties. Students recognised technology 
users as occupying 'marked' (Brekhus, 2007) social subjectivities that were conspicuously uncomfortable and socially risky. They therefore widely constructed the interactive app as somewhat uncomfortable to use. Thirdly, the students constructed the app as a threat to their sense of themselves as 'good' academic subjects. Many students saw the app as going against their academic sensibilities, seeing it as an unprofessional and distracting device.

\section{Unfitting: interactives apps as unsuitable for a lecture context}

A key pedagogical rationale for our introduction of the interactive app within lectures was to engender a shift from passive to (inter)active learning. Our motivation to introduce technology is consistent with a compelling amount of educational technology iterature that highlights the potential of educational technologies for supporting social- and cognitive- constructivist learning (Jonassen \& Reeves, 1996; Oliver, 2002; Woo \& Reeves, 2007). While we positioned the use of the online space as offering a new and beneficial learning approach, many students were less convinced, appearing to favour a traditional lecture approach. As Covill (2011, p. 98) warns, educators' assumptions about learning in lectures may not match student experiences:

Professors who advise students that they are going to switch to a method that will increase students' engagement and deepen their learning is likely to be met with confusion by students who already believe they are getting these benefits from traditional lectures

Consistent with Covill's (2011) study, many of the students also responded with discomfort and resistance to the interactive app in the lectures. Here, the students saw the lecture as an "island of meaning" (Zerubavel, 1997, p. 11). The lecture was a concept dominantly understood as having a distinctive cultural value and meaning that was not going to be easily changed. For example, several students discussed what they wanted out of lectures:

In the lectures I want to get knowledge. It's information for my assignments that I want. In the seminars we can then talk about it, but in the lectures I want to just be told what I need to know. [Focus Group 1]

In the lectures I just want more information about the subject. But I hope to gain more in-depth knowledge from the seminars so I can speak to the tutor about anything I am concerned about. It is different from the lecture, I just want to get, like, the new information [in the lecture] [Focus Group 2]

In another group, the students rallied around one particular comment about how the app interfered with the traditional notion of the lecture:

I don't prefer using the app in the lectures. I prefer being told things instead of you doing it yourself. [Focus Group 5]

To this comment, her peers responded enthusiastically:

Yeah, I do as well.

Yeah, I prefer someone just speaking at me giving me factual information.

[Focus Group 5] 
Similarly, Focus Group 6 started out their discussion emphasising that they value getting "information from friends" and "group work" [Focus Group 6] in seminars, but quickly shut down the suggestion that the interactive app could help facilitate similar learning situations in lectures. This was not the sort of learning that they ideally wanted for the lecture experience:

But in lectures It's a hassle isn't it

You only have ten minutes to set up

Yeah, I prefer just old school teaching

$[\ldots]$

Wouldn't you do [interactive learning] in a seminar, though?

Yeah, it's better in a seminar than a lecture.

It's just better. [Focus Group 6]

Here, it appears that many students believe that they may learn well through interactive tasks involving active knowledge construction but are nonetheless reluctant to redefine their learning role within lectures. It is ironic that these students reported using technology as a hassle, given the extent to which students can go out of their way to use their mobile phones for social purposes during class time (Wallace, 2011). Nonetheless, the theme of technology getting in the way of their idealised view of the lecture was sustained in multiple focus groups.

We contend that there is a broad socio-cultural factor at play in this scenario. The concept of the lecture is a longstanding "island of meaning" (Zerubavel, 1997, p. 11) that is well sedimented in academic and cultural discourse (Brown \& Race, 2014; Di Leonardi, 2007; Wilson \& Korn, 2007). The lecture is not only a pedagogical activity, then, but also a cultural one. It is something students anticipate, and that often induces thrill in students who have looked forward to the experience of this 'grown up learning' for several years prior to making it to university. Sitting in a lecture receiving information from the 'sage on the stage' is an image that exists in popular culture and remains dominant across educational institutions (Covill, 2011). It also exists as an image of prestige designed to lure students on university prospectuses and websites (Drew, 2013). Thus, introducing the interactive app in a way that subverts this image was met with resistance from students who can see cultural as well as pedagogical value in the didactic lecture.

Given the continued dominance of this traditional construction of the lecture across courses at universities, a lone course in which an interactive app is introduced to disrupt this model may do little to subvert the dominant model (Gikas \& Grant, 2013). Again following Covill (2011, p. 98), we see that:

...it would be highly difficult for a professor to sustain an active approach in an institution where the lecture method prevails. Imagine trying to convince students that a particular teaching method is superior when all of the other professors that these students have appear to be contentedly using an "inferior" method. To be working against the predominant culture, is not realistic. 
Furthermore, the notion that listening to an educator lecture while students take notes is not necessarily perceived by students to be passive per se (Covill, 2011; Wilson \& Korn, 2007). Indeed, students could be very active sorting, organising and classifying in their minds without necessarily needing to physically interact with their environments. This approach is highlighted, for example, in the literature on multimedia design, which emphasises the role of lecture slides in signalling, directing and segmenting information in order to support lecture participants' active internalisation of data (Mayer, 2009; Moreno \& Mayer, 2007). In other words, these Piagetian lone scientist students appeared to find non-interactive lecture presentations valuable for developing their mental schemata, and were uncomfortable with their lecturer unsettling this through the introduction of the interactive app.

Furthermore, there is a challenge in using educational technologies to build upon or supplement a traditional approach. We focused in this study on how to integrate an app into a traditional on-campus course structure. Here, we provided a lecture with an educational app. As others have argued (Pedro et al., 2018) there is a risk here in assuming that a technology can be augmented into a traditional classroom in a way that does not disturb its overall ecosystem. Perhaps, there is a need to approach app integration in a way that does not merely supplement traditional education, but rather develops an educational ecosystem in which the app is integral to how learning takes place. As Author 1 has argued elsewhere (2017), the placement of technologies in supplemental roles creates a situation in which educators and students use technologies for augmenting traditional learning, rather than wholesale re-considering how learning might take place. This is, indeed, all the more relevant given that the very app that we selected for this study - Collaborate Ultra - is designed primarily for lectures to take place remotely, not in-person.

Thus, successful integration of educational technologies is significantly more difficult than simply introducing opportunities for (inter)active mobile learning. We contend that educational technologists and educators must acknowledge that a challenge for introducing educational technologies exists within cultural discourse itself (Chan et al., 2015; Covill, 2011). Solitary attempts to introduce an interactive app and reconstruct the pedagogical concept embedded in the notion of 'the lecture' ignore the fact that there exist pre-conceived ideas and legitimate student desires about what should be involved in a lecture, and what students want to be taking place during this time. Students, therefore, tended to construct the interactive app as unfitting for their idealised notions of the lecture, and rejected it on those grounds.

\section{Uncomfortable: the interactive app as a risk to social status}

A second salient theme that emerged out of the interviews was students' constructions of the app as being uncomfortable. Students had social anxieties about having their questions and responses publicly visible to peers. Many therefore resisted using the technologies out of a fear of having their responses scrutinised by both lecturer and peers. In social media studies, the user who is reluctant to make their presence visible is labelled the 'lurker' (Dennen, 2008; Preece, Nonnecke, \& Andrews, 2004). A lurker might browse through the social media space, but resists contributing due to factors including shyness, desire for privacy, fear of aggressive respondents, and lack of interest (Preece et al., 2004). Similarly, in our study, students 
consistently highlighted the social risks of posting. This discussion emerged in all eight focus group interviews.

We argue that what was emergent during these discussions was students' concerns about what Brekhus $(2007,1998)$ labels 'marked' and 'unmarked' subjectivities. A marked subjectivity is one that is set apart, and therefore made more conspicuous than safer, and privileged, unmarked subjectivities. Following Brekhus, students saw the educational technology users as being marked subjects. They became members of the cohort who stood out as being different and abnormal. This difference was widely seen as an undesirable trait because it carried with it certain social risks:

You feel like you are on your own when you are told to get on [the app ...]. Also, when people answer the name comes up [on the lecture screen] and they don't want to be wrong. I feel like some people don't want their name put up there so it wouldn't matter what they say [Focus Group 8]

People laugh at you if you do the activities where you write on the screen.

[Focus Group 7]

Similarly, Focus Group 8 discussed what they saw to be jostling to appear 'cool' and 'aloof' taking place within the lecture theatre:

You know when you are in school and you have the cool kids and then they take the mick out of other people? Whatever workplace you are at you have people that are really popular and people that are not in most schools and whatever...

...Like, some think they are too cool to use the app...

...Yeah. To do it is like something the geeks want to do, and things like that [Focus Group 8]

Focus Group 1 corroborated these claims:

You know you're not the only person doing it. Like, I hate being the first person to like answer one of the questions, because...

...Oh nah I don't like that...

...It's like, oh she's a nerd. [Focus Group 1]

Avoiding using the interactive app altogether, or being a silent technology 'lurker', is therefore seen as a socially safe activity. Returning to Brekhus, we can see here that "the 'marked' holds far more social weight than the 'unmarked' in identity attribution" (Brekhus, Brunsma, Platts, \& Dua, 2010, pp. 64-65). Here, then, there are high-stakes consequences for using the app. Socially, students may find themselves as losing - or failing to gain - social capital as a result of being marked as 'losers', 'wrong' or 'nerds'. Loss of social capital impacts not only students' sense of their ability to interact with peers in 
social and academic settings, but also indicates the possibility that they might miss future opportunities for further building valuable social capital amongst academic equals if they become marked.

Thus, remaining unmarked enables students to preserve their social capital. Unmarked students can learn under the radar and exist within the larger cohort without being noticed or pointed out as abnormal. There are certain privileges that extend from this normativity - the privilege of moving through the lecture space without being singled out and the privilege of being able to learn without scrutiny. Students who occupy a normative and therefore 'unmarked' learner subjectivity when avoiding the app use garner access to these privileges, and this provides social incentive to avoid the interactive app in the lecture theatre.

This construction of the interactive app as being an 'uncomfotable' tool that positions students as 'vulnerable' challenges the idea that technology use is an activity that youths naturally gravitate towards (Prensky, 2001; Selwyn, 2012). While being on social networking is an almost compulsory element of mainstream western youth culture in the twenty-first century, social networking is usually a youth-led practice that takes place for social rather than educational reasons (Boyd, 2014; Pachler, Seipold, \& Bachmair, 2012). By contrast, our educational technology intervention was teacher-led, and not on the students' terms. Secondly, even in youth-led social networking spaces, it is now widely recognised that youths are heavily involved in risk management, inasmuch as their social media posts are carefully curated to project a particular self-image (Boyd, 2014; Davis \& Gardner, 2013). In creating an academic online space, we inadvertently created a social space that students constructed as uncomfortable and risky, which significantly influenced students' choices to reject the interactive app.

\section{Unacademic: the interactive app as a disruption of students' sense of themselves as 'good' students}

A significant amount of literature on mobile learning highlights that mobile phones can be seen as a distraction from learning (Liu, Li, \& Carlsson, 2010; Gikas \& Grant, 2013; Kuznekoff \& Titsworth, 2013; Thomas \& O’Bannon, 2013; Pedro et al., 2018). There is an assumption from many educators that mobile phones in class interrupt learning, creating student hesitance to be seen on the devices (Kuznekoff \& Titsworth, 2013). Similarly, many students have highlighted how they can find mobile phones a distraction, particularly when push notifications appear on screen. Furthermore, the ability for the devices to emit loud noises such as the ringing from incoming calls and screen brightness means they have the capacity to distract not only the phone user, but surrounding students as well (Thomas \& O'Bannon, 2013). While there appears to be some evidence that proficient students can multitask while using the devices (Kuznekoff \& Titsworth, 2013), there nonetheless remains an undercurrent of resistance to mobile phones for learning within university discourse.

It is no surprise, then, that several students also saw the use of interactive apps as contravening their sense of themselves as 'good' academically inclined learners. Building upon the students' constructions of 'ideal' lectures as didactic learning experiences, several students discussed that the use of mobile phones was not the 'right' way for them to behave in lectures and seminars. Several students, for example, discussed how the right way to behave was instead to dedicate focus upon the lecturer's presentation: 
So, I always get side tracked if I'm doing something else so if I focus on [the

lecturer] then I won't, like, I'll do the right thing [Focus Group 3]

I won't concentrate on my work if I'm busy doing the activities. [Focus Group 7]

If I'm on the phone I'm worried [the lecturer] will think I'm not paying attention and doing the wrong thing [Focus Group 8]

People usually hide their phones under the desk. It's weird just having it out for the lecturer to see [Focus Group 3]

Kasworm (2005) argues that the ideal academically inclined student image tends to be linked to notions of being serious, committed, purposeful, and attentive. These ideals are reinforced through education institutions' cultures; cultures that often continue to actively work to dissuade students from using mobile technologies in classrooms (Liu et al., 2010). Idealised notions of the 'committed' and 'attentive' student could indeed conflict with perceptions that phones are a distraction and procrastination tool. Indeed, the above quotes show how some students in this study continued to see mobile technologies as unacademic, even when the interactive apps were encouraged by the lecturer.

Furthermore, academically inclined students can indeed be very active and busy during lectures before interactive apps are introduced. With a lecturer talking at the front of class, students often feel compelled to 'keep up' by both note taking and actively listening (Boyle, 2011). Indeed, scholars from information processing theories (Mayer, 2009; Moreno \& Mayer, 2007) tend to highlight the ways in which lecture slides, lecturer speech and note taking combined can lead to cognitive overload and the subsequent forgetting of key information. Introducing an interactive app could add to the information being provided (Pedro et al., 2018) and therefore interrupt a student's note taking - which they may find more important (Boyle, 2011; Di Leonardi, 2007). Here, whereas we valued in-time participation in a learning activity, the students may have valued record keeping more highly, so that they could engage in study at a later date.

We are not implying that the phones are necessarily negative for learning, or indeed necessarily a distraction for students. Instead, we are highlighting how they have the capacity to be constructed (Brekhus et al., 2010; Zerubavel, 1997) by both students and educators as unacademic devices, which can feed into students' hesitance to embrace them in lectures. Even when students are encouraged to use interactive apps on mobile devices, they can continue to treat them with caution. The apps could either be seen as a potential 'lure' away from learning, an added degree of work on top of the work they already do during a lecture, or indeed a device seen to be used by people less interested in being academically inclined students.

\section{Conclusions}

We see interactive mobile apps not as causing change across a cohort; instead, we see the students constructing the educational technologies in complex ways in relation to their own desires, anxieties and contexts (Oliver, 2013). Given the opportunity to interact with an interactive mobile app in lectures, a plurality of our students resisted for 
many complex reasons beyond the mere technological affordances or use values they saw in the technologies. In this study, many students remained very concerned about diverging from the learning identities that they were comfortable with in this sort of space, because it didn't seem fitting for a lecture experience, socially comfortable, or academically appropriate.

We therefore consider the introduction of an interactive mobile app in our lectures for this study to be something of a false start. We came up against resistance that we did not expect, which we found to be very complex and multifaceted. To be sure, we see significant failings in many areas of our implementation. Technologically, the software we settled on turned out to be a drain on students' batteries, and despite several attempts to 'teach' students how to log-on, several students continued to note that they were still unsure how to do so.

However, in this paper, we have focussed on some of the underlying social and cultural aspects of the experience that led students to construct the interactive mobile app as unfitting, uncomfortable and unacademic. Indeed, we believe that students used their social and cultural perspectives when choosing to construct the technological intervention in the ways they did, which leads us to reject a technological determinist approach to educational technologies. By examining the social and cultural dimensions of technology interventions, scholars can open up debate about how and why students construct educational technologies in the ways they do, which may lead to more effective and sensitive uses of technologies for education.

On a closing note, we believe examining the social dimensions of educational technologies also highlights the limitations of the imposition of change. In taking up a technological determinist approach, educators can undervalue students' agency to construct educational technologies in ways that are meaningful to their own lived experiences. Perhaps through consulting students, educators can deconstruct what Fielding (2004, p. 295) calls "the presumptions of the present" in order that students and teachers can work together in co-creating meaningful educational technology experiences. As Pedro, Barbados and Santos (Pedro et al., 2018, p. 13) recently argued, there is a need for "a shift from a data-driven use of m-learning to collaborative-driven practices". Thus, we see it fitting to conclude with the students' voice. By co-constructing the meaning of educational technologies with students, we might in the future be able to come to more mutually beneficial teaching and learning arrangements:

I think he should ask us if we want to do it...

Yeah, before...

I feel like if he asks everybody in the lecture then most people would prefer not to have it. [Focus Group 5] 
Competing interests

The authors declare that they have no competing interests.

\section{Publisher's Note}

Springer Nature remains neutral with regard to jurisdictional claims in published maps and institutional affiliations.

Received: 29 March 2018 Accepted: 25 September 2018

Published online: 30 October 2018

\section{References}

Attride-Stirling, J. (2001). Thematic networks: an analytic tool for qualitative research. Qualitative Research, 1(3), $385-405$.

Bijker, W., \& Pinch, T. (1984). The social construction of facts and artefacts: or how the sociology of science and the sociology of technology might benefit each other. Social Studies of Science August, 14(3), 399-441.

Boyd, D. (2014). It's complicated. New Haven: Yale University Press.

Boyle, J. R. (2011). Thinking strategically to record notes in content classes. American Secondary Education, 40, 51-66.

Brekhus, W. (1998). A sociology of the unmarked: redirecting our focus. Sociological Theory, 16(1), 34-61.

Brekhus, W. (2007). The Rutgers school: a Zerubavelian culturalist cognitive sociology. European Journal of Social Theory, 10(3), $448-464$.

Brekhus, W., Brunsma, D., Platts, T., \& Dua, P. (2010). On the contributions of cognitive sociology to the sociological study of race. Sociology Compass, 4(1), 61-76.

Brown, S., \& Race, P. (2014). 500 tips for further and continuing education lecturers. London: Routledge.

Chan, N., Walker, C., \& Gleaves, A. (2015). An exploration of students' lived experiences of using smartphones in diverse learning contexts using a hermeneutic phenomenological approach. Computers \& Education, 82, 96-106.

Chi, M. T. (2009). Active-constructive-interactive: a conceptual framework for differentiating learning activities. Topics in Cognitive Science, 1(1), 73-105.

Clarke, V., \& Braun, V. (2013). Teaching thematic analysis: overcoming challenges and developing strategies for effective learning. The Psychologist, 26(2), 120-123.

Covill, A. E. (2011). College students' perceptions of the traditional lecture method. College Student Journal, 45(1), 92-102.

Davis, K., \& Gardner, H. (2013). The app generation: how today's youth navigate identity, intimacy, and imagination in a digital world. New Haven: Yale University Press.

Dennen, V. P. (2008). Pedagogical lurking: student engagement in non-posting discussion behavior. Computers in Human Behavior, 24(4), 1624-1633.

Di Leonardi, B. C. (2007). Tips for facilitating learning: the lecture deserves some respect. The Journal of Continuing Education in Nursing, 38(4), 154-161.

Drew, C. (2013). Elitism for sale: promoting the elite school online in the competitive educational marketplace. Australian Journal of Education., 57(2), 174-184.

Fielding, M. (2004). Transformative approaches to student voice: theoretical underpinnings, recalcitrant realities. British Educational Research Journal, 30(2), 295-311.

Gikas, J., \& Grant, M. M. (2013). Mobile computing devices in higher education: student perspectives on learning with cellphones, smartphones \& social media. The Internet and Higher Education, 19, 18-26.

Jonassen, D. H., \& Reeves, T. C. (1996). Learning with technology: using computers as cognitive tools. In D. H. Jonassen (Ed.), Handbook of research for educational communications and technology, (pp. 693-719). New York: Macmillan.

Jones, A., \& Bissell, C. (2011). The social construction of educational technology through the use of authentic software tools. Research in Learning Technology, 19, 285-297.

Kasworm, C. (2005). Adult student identity in an intergenerational community college classroom. Adult Education Quarterly, $56(1), 3-20$.

Kear, K., Jones, A., Holden, G., \& Mark, C. (2016). Social technologies for online learning: theoretical and contextual issues. Open Learning, 31(1), 42-53.

Kuznekoff, J., \& Titsworth, S. (2013). The impact of mobile phone usage on student learning. Communication Education, 62(3), 233-252. https://doi.org/10.1080/03634523.2013.767917.

Liu, Y., Li, H., \& Carlsson, C. (2010). Factors driving the adoption of m-learning: an empirical study. Computers \& Education, 55(3), 1211-1219.

Longhurst, R. (2003). Semi-structured interviews and focus groups. In Clifford, N., Cope, M., Gillespie, T. \& French, S. (Eds.), Key Methods in Geography, 117-132. London: SAGE.

Mayer, R. (2009). Multimedia learning, (2nd ed., ). Cambridge: Cambridge University Press.

Moreno, R., \& Mayer, R. (2007). Interactive multimodal learning environments. Educational Psychology Review, 19(3), $309-326$.

Oliver, M. (2011). Technological determinism in educational technology research: some alternative ways of thinking about the relationship between learning and technology. Journal of Computer Assisted Learning, 27(5), 373-384.

Oliver, M. (2013). Learning technology: theorising the tools we study. British Journal of Educational Technology, 44(1), 31-43.

Oliver, R. (2002). The role of ICT in higher education for the 21st century: ICT as a change agent. Perth Australia: Edith Cowan University Press.

Pachler, N., Seipold, J., \& Bachmair, B. (2012). Mobile learning: some theoretical and practical considerations. In K. Friedrich, M. Ranieri, N. Pachler, \& P. Theux (Eds.), The "My Mobile" handbook. Guidelines and scenarios for mobile learning in adult education, (pp. 11-16). London: European Union: Lifelong Learning Programme.

Pedro, L., Barbosa, C., \& Santos, C. (2018). A critical review of mobile learning integration in formal educational contexts. International Journal of Educational Technology in Higher Education., 15(10), 1-15.

Preece, J., Nonnecke, B., \& Andrews, D. (2004). The top five reasons for lurking: improving community experiences for everyone. Computers in Human Behavior, 20(2), 201-223.

Prensky, M. (2001). Digital natives, digital immigrants part 1. On the Horizon, 9(5), 1-6. 
Selwyn, N. (2012). Making sense of young people, education and digital technology: the role of sociological theory. Oxford Review of Education, 38(1), 81-96.

Selwyn, N., \& Facer, K. (2014). The sociology of education and digital technology: past, present and future. Oxford Review of Education, 40(4), 482-496.

Smith, E. (2016). "A real double-edged sword:" undergraduate perceptions of social media in their learning. Computers \& Education, 103, 44-58.

Sung, Y., Chang, K., \& Liu, T. (2016). The effects of integrating mobile devices with teaching and learning on students' learning performance: a meta-analysis and research synthesis. Computers \& Education, 94, 252-275.

Thomas, K., \& O'Bannon, B. (2013). Cell phones in the classroom: preservice teachers' perceptions. Journal of Digital Learning in Teacher Education, 30(1), 11-20.

Vaismoradi, M., Jones, J., Turunen, H., \& Snelgrove, S. (2016). Theme development in qualitative content analysis and thematic analysis. Journal of Nursing Education and Practice, 6(5), 100.

Wallace, P. (2011). M-learning: promises, perils, and challenges for k-12 education. New Horizons Online Journal http://archive. education.jhu.edu/PD/newhorizons/Journals/Winter2011/Wallace. Accessed 24 Aug 2018.

Webster, A. (2013). Digital technology and sociological windows. In N. Prior, \& K. Orton-Johnson (Eds.), Digital sociology, (pp. 227-233). Basingstoke: Palgrave.

Wilson, K. \& Korn, J. H. (2007). Attention during lectures: beyond ten minutes. Teaching of Psychology, 34(2), 85-89.

Woo, Y., \& Reeves, T. C. (2007). Meaningful interaction in web-based learning: a social constructivist interpretation. The Internet and Higher Education, 10(1), 15-25

Wu, W. H., Wu, Y. C. J., Chen, C. Y., Kao, H. Y., Lin, C. H., \& Huang, S. H. (2012). Review of trends from mobile learning studies: A meta-analysis. Computers \& Education, 59(2), 817-827.

Zerubavel, E. (1997). Social mindscapes: an invitation to cognitive sociology. Cambridge: Harvard University Press.

\section{Submit your manuscript to a SpringerOpen ${ }^{\circ}$} journal and benefit from:

- Convenient online submission

- Rigorous peer review

- Open access: articles freely available online

High visibility within the field

- Retaining the copyright to your article

Submit your next manuscript at $\boldsymbol{\nabla}$ springeropen.com 